\title{
Response of Sorghum Accessions against Newly Documented Pathotypes 5 and 6 of Head Smut Pathogen, Sporisorium reilianum
}

\author{
Louis K. Prom ${ }^{*}$, Ramasamy Perumal ${ }^{2}$, Thomas Isakeit ${ }^{3}$, Saradha Erattaimuthu ${ }^{3}$, Clint Magill ${ }^{3}$ \\ ${ }^{1}$ USDA-ARS, Crop Germplasm Research Unit, College Station, TX, USA \\ ${ }^{2}$ Department of Agronomy, Agricultural Research Center, Kansas State University, Hays, KS, USA \\ ${ }^{3}$ Department of Plant Pathology and Microbiology, Texas A\&M University, College Station, TX, USA \\ Email: *louis.prom@usda.gov
}

How to cite this paper: Prom, L.K., Perumal, R., Isakeit, T., Erattaimuthu, S. and Magill, C. (2021) Response of Sorghum Accessions against Newly Documented Pathotypes 5 and 6 of Head Smut Pathogen, Sporisorium reilianum. American Journal of Plant Sciences, 12, 432-443. https://doi.org/10.4236/ajps.2021.123028

Received: February 8, 2021

Accepted: March 28, 2021

Published: March 31, 2021

Copyright ( 2021 by author(s) and Scientific Research Publishing Inc. This work is licensed under the Creative Commons Attribution International License (CC BY 4.0).

http://creativecommons.org/licenses/by/4.0/ (c) (i) Open Access

\begin{abstract}
This study was conducted to identify resistance sources against the newly documented pathotypes (P5 and P6) of Sporisorium reilianum, causing sorghum head smut. A subset of 67 sorghum association panel (SAP) accessions, 29 in 2017 and 38 in 2018 along with checks BTx635 (resistant) and BTx643 (susceptible) were screened in the greenhouse against P5 and P6 pathotypes in two separate experiments in both years. At 18 to 20 days after planting, accessions were inoculated by injecting the seedlings below the apical meristem with sporidial suspensions following an established inoculation procedure. Three accessions (PI656091, PI533919, and PI533821) in 2017 and 17 accessions (PI597961, PI656071, PI656048, PI576435, PI534075, PI534145, PI656057, PI576437, PI651492, PI656014, PI656025, PI655999, PI656010, PI656082, PI534123, PI533927, PI656100) in 2018 were identified as potential resistant sources to both $\mathrm{P} 5$ and $\mathrm{P} 6$ pathotypes of $S$. reilianum. These SAP accessions are new sources that can be further used to develop new breeding parental lines and hybrids and mapping populations for quantitative trait loci markers closely linked to head smut resistance.
\end{abstract}

\section{Keywords}

Sorghum, Sporisorium reilianum, Head Smut, Pathotype, Resistance

\section{Introduction}

Climatic and other associated changes due to abiotic stresses such as drought and cold will likely increase plant diseases caused by fungal pathogens, adding to the challenge of increasing food production to meet the demands of an increas- 
ing world population, which is expected to reach around 9.1 billion by 2050 [1]. Host plant resistance is one of the top research priorities to rapidly screen the available genetic resources using established inoculation procedures in sorghum. Sorghum is the fifth most important cereal crop in global commerce and is used primarily as food and fodder in diverse growing regions, especially in the drier tropics [2] [3] [4] [5]. The disease, head smut, incited by Sporisorium reilianum (Kühn) Langdon and Fullerton (syns. Sphacelotheca reiliana (Kühn) G. P. Clinton, and Sorosporium reilianum (Kühn) McAlpine), hampers the productivity and quality of the crop and therefore, poses a potential threat to food security in many countries [3] [4] [6] [7] [8]. The head smut pathogen infects at the seedling stage, but symptoms are not expressed until panicle initiation. Infected plants do not produce grain. $S$. reilianum is one of the few smut pathogens not controlled by seed treatment, leaving host resistance as the only practical way to control this disease [8].

Sorghum mono-cropping, planting susceptible hybrids, and the appearance of new virulent pathotypes in the United States (Table 1), China, and other sorghum growing regions have increased the incidence of head smut [3] [4] [6] [7] [8] [9] [10] [11]. In the 1990s, a head smut epiphytotic in China covered about 58 thousand hectares with an average incidence ranging from 18 to over $80 \%$ [4] [12]. Ngugi et al. [13] noted that $73 \%$ to $75 \%$ of farmers' fields surveyed in Western Kenya were affected by head smut. Head smut is considered as an important disease in Cameroon, Guinea, and Mali, West and Central Africa [14]. Esele [3] also noted three common sorghum smut diseases (covered, loose, and head smut) that are of economic importance in the horn of Africa, causing yield losses of 5\% - 80\%. In the United States, head smut yield losses ranging from $4 \%$ to $80 \%$ have been recorded in commercial hybrid fields [6] [11] [13]. Recently, a number of sorghum fields in south Texas, USA; as well as Tamaulipas and Ocotlan, Mexico were observed with significant infestation and yield losses [10].

Once the teliospores enter the soil, head smut will persist in the field for a decade even with proper disease management strategies such as crop rotation and the use of fungicide seed treatment [15] [16]. The disease cycle is initiated when germinating sorghum seeds stimulate the teliospores in the soil to start growing in response and the pathogen develops dikaryotic hyphae that penetrate the meristematic tissue of the seedling [6] [12] [17]. The colonization and sorus development which follows infection in the primary shoot are the result of invasion of the apical meristem at the beginning of the infection process [18]. Characteristic symptoms of head smut include smutted panicles, sterile or phyllodied panicles, and stunting (Figure 1), due to the lack of peduncle elongation [8] [18]. Previously, four pathotypes ( 1 - 4) were known to exist in the USA [9] [19]. In 2011, two new pathotypes (P5 and P6) were identified among head smut isolates collected from south Texas, an area with high density of grain sorghum production [9]. The impact of the new pathotypes P5 and P6 [9] and other fac- 
tors, including unpredictable weather changes will warrant deployment of host resistance and identification of new sources from the unexplored diversified sorghum germplasm.

Hence, this research was conducted with an objective to identify new sources of resistance against two new pathotypes (P5 and P6) of head smut pathogen, $S$. reilianum from the sorghum association panel accessions following a modified inoculation procedure in the greenhouse.

Table 1. Pathotype classifications based on resistant (R) and susceptible (S) response by the sorghum differentials.

\begin{tabular}{ccccccccc}
\hline & \multicolumn{7}{c}{ Pathotype } \\
\cline { 2 - 7 } Differential & \multicolumn{7}{c}{ Frederiksen and Reyes (1980) } & Prom et al. (2011) \\
\cline { 2 - 7 } & $\mathrm{P}^{*}$ & $\mathrm{P}^{*}$ & $\mathrm{P}^{*}$ & $\mathrm{P} 4$ & $\mathrm{P} 4 \mathrm{~A}$ & $\mathrm{P} 5$ & $\mathrm{P} 6$ \\
\hline Tx7078 & $\mathrm{S}$ & $\mathrm{S}$ & $\mathrm{S}$ & $\mathrm{S}$ & $\mathrm{S}$ & $\mathrm{S}$ & $\mathrm{R}$ \\
SA 281 (Early Hageri) & $\mathrm{R}$ & $\mathrm{S}$ & $\mathrm{S}$ & $\mathrm{R}$ & $\mathrm{S}$ & $\mathrm{R}$ & $\mathrm{R}$ \\
Tx414 (SC414) & $\mathrm{R}$ & $\mathrm{R}$ & $\mathrm{S}$ & $\mathrm{S}$ & $\mathrm{R}$ & $\mathrm{R}$ & $\mathrm{S}$ \\
SC170-6-17 (TAM2571) & $\mathrm{R}$ & $\mathrm{R}$ & $\mathrm{R}$ & $\mathrm{S}$ & $\mathrm{S}$ & $\mathrm{S}$ & $\mathrm{S}$ \\
BTx643 (Universal susceptible) & $\mathrm{S}$ & $\mathrm{S}$ & $\mathrm{S}$ & $\mathrm{S}$ & $\mathrm{S}$ & $\mathrm{S}$ & $\mathrm{S}$ \\
BTx635 (Universal resistant) & $\mathrm{R}$ & $\mathrm{R}$ & $\mathrm{R}$ & $\mathrm{R}$ & $\mathrm{R}$ & $\mathrm{R}$ & $\mathrm{R}$ \\
\hline
\end{tabular}

Reaction type: $\mathrm{S}=$ susceptible; $\mathrm{R}$ = resistant (no head smut infection, i.e., immune). ${ }^{\star}$ pathotypes 1 and 3 have been documented on cultivars/hybrids grown in Queensland, Australia by Dodman et al. (1985).

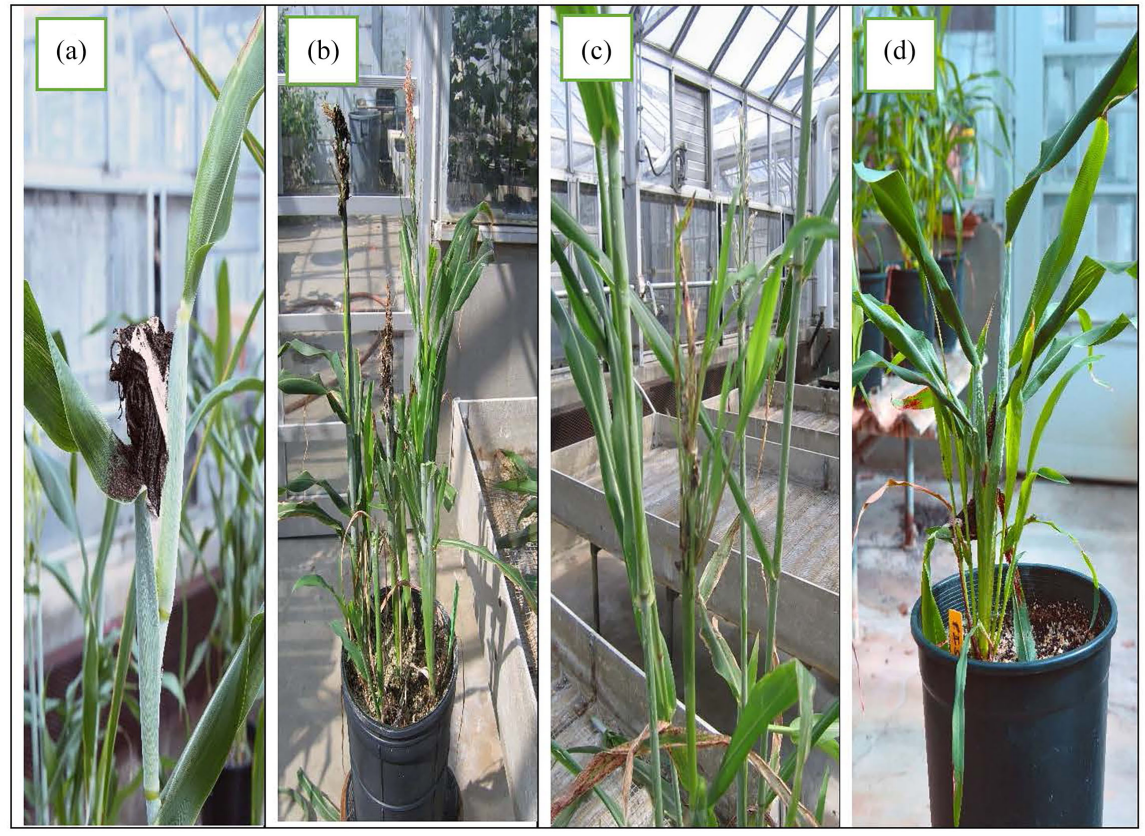

Figure 1. Manifestation of head smut infection. (a) Sorus of Sporisorium reilianum covered with a thick white-membrane; (b) Sterile panicles some of the infected panicles with smut galls; (c) Panicle with witches-broom symptom; and (d) Stunted plant infected with head smut. 


\section{Materials and Methods}

The sorghum association panel (SAP) comprised of approximately 400 accessions representing all major cultivated races (tropical lines from diverse geographic and climatic regions), and important United States breeding lines and their progenitors [20] [21]. A subset of 67 SAP accessions were obtained by the USDA-ARS, Plant Genetic Resources Conservation Unit, Griffin, Georgia. Of the 67 accessions, 29 in 2017 and 38 in 2018 along with checks BTx635 (resistant) and BTx643 (susceptible) were screened against two pathotypes P5 and P6 of the head smut pathogen in two separate experiments. Each accession in each experiment was planted in 3-gallon pots filled with Metro Mix 200 (Sun Gro Horticulture, Agawam, MA) and thinned to five plants after germination. Plants were grown in the greenhouse at $25^{\circ} \mathrm{C} \pm 2{ }^{\circ} \mathrm{C}$ under a 12-hour photoperiod provided by fluorescent. A complete randomized block design with three replications was used in both years. In each experiment, we used a mixture of two $S$. reilianum isolates for each pathotype. Isolates 03 HSC from Corpus Christi, TX and $16 \mathrm{HSW}$ from Weslaco, TX was used for pathotype 5, and isolates $08 \mathrm{HSW}$ and 14 HSW from Weslaco, TX was used for pathotype 6, because of their aggressive virulence and common presence in Texas [9].

The inoculum preparation and inoculation method were as previously described by Perumal et al. [22]. Briefly, sporidial colonies of pathotypes 5 and 6 were placed in separate flasks containing potato dextrose broth. The flasks were placed on a rotary shaker set at $150 \mathrm{rpm}$ for $4 \mathrm{~d}$ under $25^{\circ} \mathrm{C}$ room temperature to allow for multiplication of the yeast-like spores. The sporidial suspension was filtered into a sterile flask through layers of cheesecloth and adjusted to a concentration of $1 \times 10^{5}$ spores $\mathrm{ml}^{-1}$. The sporidial suspensions were used to inoculate five plants in each replicate. All 5 plants in each replication were inoculated by injection below the apical meristem of 18 to 20 days-old seedlings. Each plant was injected with 0.5 to $1.0 \mathrm{ml}$ of sporidial suspension using a Precision Glide Needle \# $22 \mathrm{G} \times 1$ in. (Becton, Dickinson and Co., Franklin Lakes, NJ) attached to a 30-ml hypodermic syringe. Plants were evaluated at heading. Plants without symptoms (Fully-developed-grains in the main tiller and no sori) were classified as resistant. However, such plants were further evaluated by cutting the main tiller and allowing the side tillers in the ratoon crop to grow to flowering stage. If the disease symptoms were expressed in the side tillers, then the line was classified as susceptible. Tillers without disease were classified as resistant. So, the disease rating of this host pathosystem was always binary (present or absent). Percent incidence was based on the number of infected plants per pot divided by the total number of plants inoculated and multiplied by 100 .

\section{Statistical Analysis}

The arcsine-transformed proportions variable was analyzed for differences using PROC GLIMMIX (SAS version 9.4, SAS Institute, Cary, NC). The experiment was a randomized complete block, where accessions were fixed effects and the replicate is a random block effect. The LSMEANS statement with LINES option 
was used to provide Tukey-Kramer multiple comparisons between accessions at the $5 \%$ probability level. The means were back transformed after the analysis.

\section{Results and Discussion}

Sorghum Association Panel accessions, representing wide genetic and geographical diversity available in the core sorghum germplasm collections, are being widely used to identify the chromosomal regions associated with complex traits of biotic and abiotic stresses to plant breeders, including grain yield and quality [23] [24]. The pathotype classification clearly established the resistance and susceptible performances of the breeding lines BTx635 and BTx643 respectively (Table 1). In this study, 29 accessions in 2017 and 38 accessions in 2018 were evaluated in the greenhouse along with susceptible (BTx643) and resistant (BTx635) for P5 and P6 pathotypes. The main effect of accession in both experiments screened for P5 and P6 pathotypes separately in 2017 and 2018 years were highly significant $(P<0.0001)$, indicating that the accessions responded differently when inoculated with either P5 or P6 (Table 2 and Table 3). In 2017, out of 29 accessions inoculated with P5, 18 accessions, including PI656091, PI533919, PI533839, PI651496 and resistant check BTx635 exhibited no infection (Table 2). Eleven accessions were infected when inoculated with P5 and PI533750 (100\% incidence) was the most susceptible. When the same accessions were inoculated with P6, three accessions PI656091, PI533919, and PI533821 along with BTx635, had no infection, whereas other accessions exhibited various levels of infection (Table 2). Accessions PI656099, PI651496, and PI329435 had $100 \%$ incidence when challenged with P6 and except for PI533750, PI656018, and PI656101 this level was markedly higher than the levels of other infected accessions. PI656091, PI533919, and PI533821 were resistant to both pathotypes. Fifteen accessions that exhibited a resistance response to P5 were susceptible when challenged with P6 pathotype.

In 2018, out of the 38 accessions along with two checks inoculated with P5, $50 \%$ of the accessions, including PI656071, PI656048, PI534145, PI576437, and PI656015 exhibited no infection, while PI533980, PI597968, PI655989, and PI655996 recorded 100\% incidence (Table 3). This level of infection was significantly different from the other infected accessions whose incidences ranged from $20 \%$ to $66 \%$. When the accessions were inoculated with P6, only $25 \%$ were susceptible along with susceptible check BTx643 (Table 3). Accessions PI533863, PI655986, and PI656015 recorded 100\% incidence. Twenty-nine of accessions, including PI597961, PI576435, PI534145, PI656082, and PI656100 recorded zero percent infection when inoculated with P6 pathotype. PI656033 and PI656015 showed resistance to P5 and susceptible reaction to P6 pathotype. On the other hand, 12 accessions were susceptible to P5 and resistant to P6 pathotypes. Including the resistant check BTx635, seventeen accessions (PI597961, PI656071, PI656048, PI576435, PI534075, PI534145, PI656057, PI576437, PI651492, PI656014, PI656025, PI655999, PI656010, PI656082, PI534123, PI533927, PI656100) were resistant to both $\mathrm{P} 5$ and $\mathrm{P} 6$ pathotypes. 
Table 2. Head smut greenhouse screening in 2017: Reaction of 29 SAP accessions to pathotypes 5 and 6 of Sporisorium reilianum both in the main and side tillers in the ratoon crop.

\begin{tabular}{|c|c|c|c|c|c|c|}
\hline \multirow[b]{2}{*}{ PI Accession } & \multirow[b]{2}{*}{ SC number } & \multirow[b]{2}{*}{ Origin } & \multicolumn{2}{|c|}{ Pathotype $5^{\text {a }}$} & \multicolumn{2}{|c|}{ Pathotype $6^{\mathrm{a}}$} \\
\hline & & & Reaction $^{\mathrm{b}}$ & Incidence $\%$ & Reaction & Incidence \% \\
\hline PI533750 & SC214 & India & + & $100 a^{c}$ & + & $80 \mathrm{abc}$ \\
\hline PI533961 & SC121 & South Africa & + & $75 b$ & + & $60 \mathrm{bcde}$ \\
\hline PI534114 & SC574 & Pakistan & + & $70 \mathrm{bc}$ & + & $40 \mathrm{cde}$ \\
\hline PI533789 & SC57 & Sudan & + & $70 \mathrm{bc}$ & + & $60 \mathrm{bcde}$ \\
\hline PI533871 & SC566 & Nigeria & + & $50 \mathrm{bcd}$ & + & $25 \mathrm{def}$ \\
\hline PI656078 & SC1424 & USDA, ARS & + & $50 \mathrm{bcd}$ & + & $50 \mathrm{bcde}$ \\
\hline PI533788 & SC53 & Sudan & + & $40 \mathrm{cde}$ & + & 60bcde \\
\hline PI655980 & Tx2785 & Texas, US & + & $30 \mathrm{de}$ & + & 20def \\
\hline PI533833 & SC319 & Uganda & + & $25 \mathrm{de}$ & + & $30 \mathrm{de}$ \\
\hline PI656099 & SC498 & USDA, ARS & + & $25 \mathrm{de}$ & + & $100 \mathrm{a}$ \\
\hline PI655995 & Deer & United States & + & $15 \mathrm{e}$ & + & $60 \mathrm{bcde}$ \\
\hline PI533755 & SC55 & Sudan & - & of & + & $60 \mathrm{bcde}$ \\
\hline PI533754 & SC309 & Sudan & - & of & + & $40 \mathrm{cde}$ \\
\hline PI533839 & SC303 & Nigeria & - & of & + & $50 \mathrm{bcde}$ \\
\hline PI533766 & SC265 & Burkino Faso & - & Of & + & 20def \\
\hline PI533792 & SC108 & Ethiopia & - & of & + & $60 \mathrm{bcde}$ \\
\hline PI17548 & Red Amber & Australia & - & of & + & $65 \mathrm{bcd}$ \\
\hline PI656091 & $\mathrm{SC} 22$ & USDA, ARS & - & of & - & of \\
\hline PI533913 & SC66 & Sudan & - & of & + & $50 \mathrm{bcde}$ \\
\hline PI651496 & Rio & USDA, ARS & - & of & + & $100 \mathrm{a}$ \\
\hline PI533869 & SC283 & Tanzania & - & of & + & $50 \mathrm{bcded}$ \\
\hline PI533919 & SC124 & Ethiopia & - & of & - & of \\
\hline PI533855 & SC317 & India & - & of & + & $15 \mathrm{ef}$ \\
\hline PI656018 & BTx 2752 & Texas, USA & - & of & + & $90 \mathrm{ab}$ \\
\hline PI656055 & P-721 & Indiana, USA & - & of & + & $35 \mathrm{cde}$ \\
\hline PI329435 & Mashila & Ethiopia & - & of & + & $100 \mathrm{a}$ \\
\hline PI533821 & SC322 & Tanzania & - & of & - & of \\
\hline PI35038 & Sumac & Texas, USA & - & of & + & $45 \mathrm{cde}$ \\
\hline PI656101 & SC525 & USDA, ARS & - & of & + & $80 a b c$ \\
\hline BTx635 & Resistant check & Texas, USA & - & of & - & of \\
\hline BTx643 & Susceptible check & Texas, USA & + & $100 \mathrm{a}$ & + & $80 \mathrm{abc}$ \\
\hline
\end{tabular}

aplants inoculated using a modified syringe technique (Perumal et al. 2007; Prom et al. 2011). ${ }^{\text {bReaction }}$ type $+=$ head smut infection (susceptible); - = no infection (resistant). ' Mean within a column followed by the same letter(s) are not significant based on Tukey-Kramer multiple comparisons between accessions at the $5 \%$ probability level. 
Table 3. Head smut greenhouse screening in 2018: Reaction of 38 SAP accessions to pathotypes 5 and 6 of Sporisorium reilianum both in the main and side tillers in the ratoon crop.

\begin{tabular}{|c|c|c|c|c|c|c|}
\hline \multirow[b]{2}{*}{ PI Accession } & \multirow[b]{2}{*}{ SC number } & \multirow[b]{2}{*}{ Origin } & \multicolumn{2}{|c|}{ Pathotype $5^{\text {a }}$} & \multicolumn{2}{|c|}{ Pathotype $6^{a}$} \\
\hline & & & Reaction $^{\mathrm{b}}$ & Incidence $\%$ & Reaction & Incidence \% \\
\hline PI533980 & SC572 & China & + & $100 \mathrm{a}$ & - & $0 \mathrm{e}$ \\
\hline PI597968 & SC1321 & Texas, USA & + & $100 \mathrm{a}$ & + & $50 \mathrm{c}$ \\
\hline PI655989 & Redbine- 60 & Texas, USA & + & $100 \mathrm{a}$ & - & $0 \mathrm{e}$ \\
\hline PI655996 & Not known & - & + & $100 \mathrm{a}$ & - & $0 \mathrm{e}$ \\
\hline PI656019 & BTх3042 & Texas, USA & + & $66 \mathrm{~b}$ & - & $0 \mathrm{e}$ \\
\hline PI533976 & SC655 & South Africa & + & $66 \mathrm{~b}$ & - & $0 \mathrm{e}$ \\
\hline PI655978 & Tx2737 & Texas, USA & + & $66 \mathrm{~b}$ & + & $50 c$ \\
\hline PI656090 & SC1494 & USDA, ARS & + & $60 \mathrm{bc}$ & - & $0 \mathrm{e}$ \\
\hline PI564165 & $\mathrm{RT} \times 434$ & Texas, USA & + & $60 \mathrm{bc}$ & - & $0 \mathrm{e}$ \\
\hline PI642998 & Black Spanish & USDA, ARS & + & $50 \mathrm{bcd}$ & - & $0 \mathrm{e}$ \\
\hline PI656074 & SC1218 & USDA, ARS & + & $50 \mathrm{bcd}$ & - & $0 \mathrm{e}$ \\
\hline PI656022 & BTx615 & Texas, USA & + & $50 \mathrm{bcd}$ & - & $0 \mathrm{e}$ \\
\hline PI533863 & SC320 & Chad & + & $50 \mathrm{bcd}$ & + & $100 \mathrm{a}$ \\
\hline PI655986 & Caprock & Texas, USA & + & $40 \mathrm{cde}$ & + & $100 \mathrm{a}$ \\
\hline PI533965 & SC115 & Uganda & + & 33de & - & $0 \mathrm{e}$ \\
\hline PI534163 & SC599 & USDA, ARS & + & $25 \mathrm{e}$ & + & $50 \mathrm{c}$ \\
\hline PI534009 & SC441 & INDIA & + & $25 \mathrm{e}$ & + & $25 \mathrm{~d}$ \\
\hline PI656002 & BOK11 & Oklahoma, USA & + & $25 \mathrm{e}$ & + & $25 \mathrm{~d}$ \\
\hline PI598069 & RTx2909 & Texas, USA & + & $20 \mathrm{e}$ & - & $0 \mathrm{e}$ \\
\hline PI597961 & SC1077 & Texas, USA & - & of & - & $0 \mathrm{e}$ \\
\hline PI656071 & SC1019 & USDA, ARS & - & of & - & $0 \mathrm{e}$ \\
\hline PI656048 & Malisor84-1 & Mali & - & of & - & $0 \mathrm{e}$ \\
\hline PI576435 & SC1104 & Uganda & - & of & - & $0 \mathrm{e}$ \\
\hline PI534075 & SC348 & Nigeria & - & of & - & $0 \mathrm{e}$ \\
\hline PI534145 & SC91 & Rhodesia & - & of & - & $0 \mathrm{e}$ \\
\hline PI656033 & $60 \mathrm{M}$ & USda, ARS & - & of & + & $25 \mathrm{~d}$ \\
\hline PI656057 & Not known & - & - & of & - & $0 \mathrm{e}$ \\
\hline PI576437 & SC1203 & Brazil & - & of & - & $0 \mathrm{e}$ \\
\hline PI651492 & Cowley & Texas, USA & - & of & - & $0 \mathrm{e}$ \\
\hline PI656014 & Acme Broomcorn & USDA, ARS & - & of & - & $0 \mathrm{e}$ \\
\hline PI656025 & Shan Qui Red & China & - & of & - & $0 \mathrm{e}$ \\
\hline PI655999 & Tx2784 & Texas, USA & - & of & - & $0 \mathrm{e}$ \\
\hline PI656015 & Ajabsido & Sudan & - & of & - & $100 \mathrm{a}$ \\
\hline PI656010 & RTx2536 & Texas, USA & - & of & - & $0 \mathrm{e}$ \\
\hline PI656082 & SC145 & USDA, ARS & - & of & - & $0 \mathrm{e}$ \\
\hline PI534123 & $\mathrm{SC} 13$ & Ethiopia & - & of & - & $0 \mathrm{e}$ \\
\hline PI533927 & SC224 & Ethiopia & - & of & - & $0 \mathrm{e}$ \\
\hline PI656100 & SC50 SC500 & USDA, ARS & - & of & - & $0 \mathrm{e}$ \\
\hline BТx635 & Resistant check & Texas, USA & - & of & - & $0 \mathrm{e}$ \\
\hline BTx643 & Susceptible check & Texas, USA & + & $100 \mathrm{a}$ & + & $75 \mathrm{~b}$ \\
\hline
\end{tabular}

aPlants inoculated using a modified syringe technique (Perumal et al. 2007; Prom et al. 2011). ' $R$ Reaction type $+=$ head smut infection (susceptible); - = no infection (resistant). ' Mean within a column followed by the same letter(s) are not significant based on Tukey-Kramer multiple comparisons between accessions at the $5 \%$ probability level. 
Indira et al. [4] identified 20 lines resistant to head smut including A7050, A232E, BICS 49, and Lian-Tang-Ai the Chinese pathotype 3. Further, PI961560 and SA281 were identified as resistant sources to all four Chinese head smut pathotypes [11]. In the United States, six converted sorghum accessions, including SC103-11E, SC155, SC166, and SC425 evaluated in Texas exhibited head smut resistance to pathotypes 1 to 4 [25]. Later, sorghum lines from AgriLife Research in Lubbock and College Station, Texas, Tx2935 through Tx2944 and Tx2962 through Tx2978, which were released in 2004and 2006, respectively, showed resistance to head smut pathotypes 1 to 4 [26]. Sorghum cultivar Tx7078 was susceptible to pathotypes 1 to 5 (Table 1 ) but exhibited good resistance to all Chinese pathotypes and resistant to pathotype P6 as well [9] [11]. In our study a total of 20 new resistant sources from SAP were identified for both P5 and P6 pathotypes from two years' evaluations.

S. reilianum infestation has been seen continuously in commercial hybrids over the last two decades grown in fields in the areas of northeast Mexico and southern parts of Texas. In the United States, four pathotypes 1 to 4 were established earlier by Frederiksen and Reyes [19] where, pathotypes 1 and 3 have been documented on cultivars/hybrids grown in Queensland, Australia also by Dodman et al. [27] (Table 1). Later, Zhang et al. [11] established four Chinese pathotypes with different reactions on the same host differentials used in the United States by Frederiksen and Reyes [19]. It clearly indicated that virulence studies and the disease outburst were not monitored over two decades in the United States until the new pathotypes P5 and P6 were identified by Prom et al in 2011 [9]. The increase of $S$. reilianum infestation in the grain sorghum areas of the United States and northeast Mexico might be due to the repeated usage of the available sorghum hybrids susceptible to the new pathotypes P5 and P6 and was associated with significant yield losses over the years. Also, the variability within head smut pathogen populations warrants continual evaluation of sorghum germplasm to identify potential resistance sources that would broaden the genetic base in the adapted breeding lines with wide range of resistance background.

Three different host mechanisms were earlier defined as: R1, horizontal, resistance to natural infection but susceptibility to all races following syringe inoculation; R2, vertical, specific resistance to some races of $S$. reilianum and susceptibility to others, with the same response to natural infection as to syringe inoculation; and R3, horizontal resistance to natural infection and syringe inoculation [19] [28]. However, screening with natural infection under field conditions gives unpredicted and unreliable results, due to pathogen variability and disease escapes, even in the hot spots in sorghum growing areas, due to environmental fluctuations, distribution of the teliospores, low percentage of teliospore germination, and a high level of spore dormancy in the field [8]. Hence, the modified syringe injection technique at seedling stage inoculation by Perumal et al. [22] from the original technique developed earlier by Edmunds [29] was established. The experimental results following the modified inoculation technique 
were effective and consistent to establish reliable screening procedure for resistance [9].

In sorghum, during pathogenesis, dikaryotic hyphae of the head smut pathogen can penetrate the root epidermis and colonize the meristematic tissue, including regions near the apical meristem of the sorghum seedlings [8]. Upon panicle initiation, the pathogen grows vigorously leading to the production of teliospores [8]. In some sorghum lines, there is delayed response which is akin to slow rusting found in other host pathosystems [30]. The main panicle may not be infected but upon removing it, the subsequent tiller or tillers become infected. However, if these subsequent tillers are still not infected then the line is rated as resistant, further confirming the resistance response of the line. The mechanism(s) involved in this delayed response in sorghum-head smut interaction is still unknown. This could probably be explained by rapid growth of the meristematic tissue and/or apical meristem whereby main panicle escapes the infection, although the fungus is still present. The disease is then manifested in the tillers. Hence, for the established syringe inoculation method, repeated screening is not required as the main tillers showing no symptoms were allowed to side tiller in the ratoon crop to confirm the disease reaction (susceptible or resistant). Prom et al. [9] also showed that this syringe inoculation technique is very effective.

\section{Conclusion and Significance}

Head smut incidence is continuously increasing in northern Mexico and the coastal bend of south Texas production fields where susceptible hybrids are grown. Crop management practices such as crop rotation or fungicide application are not effective, leaving the use of resistant hybrids as the only option to control this soilborne fungal disease. This study identified 20 new potential sources of resistance from the sorghum association panel (SAP) for P5 and P6 pathotypes of $S$. reilianum, which can be used in introgression breeding to develop parental lines and hybrids with head smut resistance. However, the genetic inheritance of these resistant sources needs to be explored to determine whether the resistance is controlled by either single dominant gene or by many genes.

\section{Acknowledgements}

This research (CRIS \# 3091-22000-034-00D) was supported by the US Department of Agricultural Research Service.

Mention of trade names or commercial products in this publication is solely for the purpose of providing specific information and does not imply recommendation or endorsement by the US Department of Agriculture.

\section{Conflicts of Interest}

The authors declare no conflicts of interest regarding the publication of this paper. 


\section{References}

[1] Food and Agriculture Organization of the United Nations (2009) How to Feed the World in 2050. Food and Agriculture Organization of the United Nations, Rome. http://www.fao.org/fileadmin/templates/wsfs/docs/expert paper/How to Feed the World in 2050.pdf

[2] Frederiksen, R.A. and Odvody, G.N. (2000) Compendium of Sorghum Diseases. The American Phytopathological Society, St. Paul.

[3] Esele, J.P. (2002) Sorghum and Pearl Millet Diseases in the Horn of Africa. In: Leslie, J. F., Ed., Sorghum and Millets Diseases, Iowa State Press, Ames, 383-387. https://doi.org/10.1002/9780470384923.ch64

[4] Indira, S., Xu, X., Iamsupasit, N., Shetty, H.S., Vasanthi, N.S., Singh, S.D. and Bandyopadhyay, R. (2002) Diseases of Sorghum and Pearl Millet in Asia. In: Leslie, J.F., Ed., Sorghum and Millets Diseases, Iowa State Press, Ames, 393-402. https://doi.org/10.1002/9780470384923.ch66

[5] Upadhyaya, H.D., Reddy, K.N., Vetriventhan, M., Ahmed, M.I., Krishna, G.M., Reddy, M.T. and Singh, S.K. (2017) Sorghum Germplasm from West and Central Africa Maintained in the ICRISAT Genebank: Status, Gaps, and Diversity. The Crop Journal, 5, 518-532. https://doi.org/10.1016/j.cj.2017.07.002

[6] Frederiksen, R.A. (1977) Head Smuts of Corn and Sorghum. 32nd Annual Corn and Sorghum Research Conference, Chicago, Illinois, 6-8 December 1977, 98-105.

[7] Torres-Montalvo, H., McDonald, B.A., Magill, C.W. and Frederiksen, R.A. (1998) Structure of Sporisorium reilianum Populations from Mexico, USA, and Niger. International Sorghum and Millets Newsletter, 39, 110-113.

[8] Frederiksen, R.A. (2000) Disease and Disease Management in Sorghum. In: Smith, C. and Frederiksen, R.A., Eds, Sorghum-Origin, History, Technology and Production, John Wiley \& Sons, Inc., New York, 497-533.

[9] Prom, L.K., Perumal, R., Erattaimuthu, S.R., Erpelding, J.E., Montes, N., Odvody, G.N., Greenwald, C., Jin, Z., Frederiksen, R. and Magill, C.W. (2011) Virulence and Molecular Genotyping Studies of Sporisorium reilianum Isolates in Sorghum. Plant Disease, 95, 523-529. https://doi.org/10.1094/PDIS-10-10-0720

[10] Prom, L.K., Montes-Garcia, N. and Odvody, G.N. (2014) Influence of Planting Depths on the Incidence of Sorghum Head Smut, Caused by Sporisorium reilianum. Tropical and Subtropical Agroecosystems, 17, 33-38.

[11] Zhang, F., Ping, J., Du, Z., Cheng, Q. and Huang, Y. (2011) Identification of a New Race of Sporisorium reilianum and Characterization of the Reaction of Sorghum Lines to Four Races of the Head Smut Pathogen. Journal of Phytopathology, 159, 342-346. https://doi.org/10.1111/j.1439-0434.2010.01770.x

[12] Bai, C., Liu, Y., Lu, X. and Tao, C. (2016) Progress in Sorghum Head Smut Research. 2016 International Conference on Civil, Structure, Environmental Engineering, Guangzhou, 12-13 March 2016, 317-320.

https://doi.org/10.2991/i3csee-16.2016.61

[13] Ngugi, H.K., King, S.B., Abayo, G.O. and Reddy, Y.V.R. (2002) Prevalence, Incidence, and Severity of Sorghum Diseases in Western Kenya. Plant Disease, 86, 65-70. https://doi.org/10.1094/PDIS.2002.86.1.65

[14] Marley, P.S., Diourté, M., Neya, A., Nutsugah, S.K., Sérémé, P., Katilé, S., Hess, D.E., Mbaye, D.F. and Ngoko, Z. (2002) Sorghum and Pearl Millet Diseases in West and Central Africa. In: Leslie, J.F., Ed., Sorghum and Millets Diseases, Iowa State Press, Ames, 419-425. https://doi.org/10.1002/9780470384923.ch70 
[15] Omer, E.H. and Frederiksen, R.A. (1992) Sorghum Smuts. In: de Milliano, W.A.J., Frederiksen, R.A. and Bengston, G.D., Eds., Sorghum and Millets Diseases: A Second World Review, International Crops Research Institute for the Semi-Arid Tropics, Patancheru, 245-252.

[16] Wilson, J.M. and Frederiksen, R.A. (1970) Histopathology of Resistance in the Sorghum bicolor-Sphacelotheca reiliana Interaction. Phytopathology, 60, 1365-1367.

[17] Little, C., Perumal, R., Tesso, T., Prom, L. K., Odvody, G. N. and Magill, C. (2012) Sorghum Pathology and Biotechnology-A Fungal Disease Perspective: Part 1. Grain Mold, Head Smut, and Ergot. The European Journal of Plant Science and Biotechnology, 6, 10-30.

[18] Wilson, J.M. and Frederiksen, R.A. (1970) Histopathology of the Interaction of Sorghum bicolor and Sphacelotheca reiliana. Phytopathology, 60, 828-832.

https://doi.org/10.1094/Phyto-60-828

[19] Frederiksen, R.A. and Reyes, L. (1980) The Head Smut Program at Texas A\&M. In: In: Williams, R.J., Frederiksen, R.A., Mughogho, L.K. and Bengston, G.D., Eds., Sorghum Diseases: A World Review, International Crops Research Institute for the Semi-Arid Tropics, Pantancheru, 367-372.

[20] Casa, A.M., Pressoir, G., Brown, P.J., Mitchell, S.E., Rooney, W.L., Tuinstra, M.R., Franks, C.D. and Kresovich, S. (2008) Community Resources and Strategies for Association Mapping in Sorghum. Crop Science, 48, 30-40.

https://doi.org/10.2135/cropsci2007.02.0080

[21] Prom, L.K., Ahn, E., Isakeit, T. and Magill, C.W. (2019) GWAS Analysis of Sorghum Association Panel Lines Identifies SNPs Associated with Disease Response to Texas Isolates of Colletotrichum sublineola. Theoretical and Applied Genetics, 132, 1389-1396. https://doi.org/10.1007/s00122-019-03285-5

[22] Perumal, R., Frederiksen, R.A., Prom, L.K. and Magill, C.W. (2007) Head Smut. In: Screening Techniques for Sorghum Diseases. Information Bulletin No. 76, International Crops Research Institute for the Semi-Arid Tropics (ICRISAT), Pantacheru 58-63.

[23] Ahn, E., Hu, Z., Perumal, R., Prom, L.K., Odvody, G., Upadhyaya, H.D. and Magill, C. (2019) Genome Wide Association Analysis of Sorghum Mini Core Lines Regarding Anthracnose, Downy Mildew, and Head Smut. PLoS ONE, 14, e0216671. https://doi.org/10.1371/journal.pone.0216671

[24] Prom, L.K., Cuevas, H.E., Ahn, E., Isakeit, T., Rooney, W.L. and Magill, C. (2020) Genome-Wide Association Study of Grain Mold Resistance in Sorghum Association Panel as Affected by Inoculation with Alternaria alternata alone and Alternaria alternata, Fusarium thapsinum, and Curvularia lunata combined. European Journal of Plant Pathology, 157, 783-798. https://doi.org/10.1007/s10658-020-02036-3

[25] Rooney, W.L., Collins, S.D., Klein, R.R., Mehta, P.J., Frederiksen, R.A. and Rodriquez, R. (2002) Breeding Sorghum for Resistance to Anthracnose, Grain Mold, Downy Mildew, and Head Smuts. In: Leslie, J.F., Ed., Sorghum and Millets Diseases, Iowa State Press, Ames, 273-279. https://doi.org/10.1002/9780470384923.ch47

[26] Rooney, W.L., Odvody, G.N., Shaefer, K. and Collins, S.D. (2011) Registration of Tx2935 through Tx2944 Sorghum Germplasm. Journal of Plant Registrations, 5, 128-132. https://doi.org/10.3198/jpr2010.01.0030crg

[27] Dodman, R.L., Obst, N.R. and Henzell, R.G. (1985) Races of Sorghum Head Smut (Sporisorium reilianum) in South-East Queensland. Australasian Plant Pathology, 14, 45. https://doi.org/10.1071/APP9850045

[28] Craig, J. and Frederiksen, R.A. (1992) Comparison of Sorghum Seedling Reactions 
to Sporisorium reilianum in Relation with Sorghum Head Smut Resistant Classes. Plant Disease, 76, 314-318. https://doi.org/10.1094/PD-76-0314

[29] Edmunds, L.K. (1963) Use of Sporidial Hypodermic Injection to Test Sorghum for Head Smut Resistance. Plant Disease Reporter, 47, 909-913.

[30] Shah, S.J.A., Hussain, S., Ahmed, M., Farhatullah, F. and Ibrahim, M. (2014) Characterization of Slow Rusting Resistance against Puccinia striiformis f. sp. Tritici in Candidate and Released Wheat Cultivars of Pakistan. Journal of Plant Pathology \& Microbiology, 5, Article No. 223. 